\title{
The Effect of Business Process Re-engineering Practices on Employee Performances (The Case of Essera Woreda in Dawro Zone South West ETHIOPIA)
}

\author{
Shimelis Begashaw Zemedagegnehu \\ Lecturer at Bonga University, Department of management, Bonga, Ethiopia \\ Zeleke Arko Sapore \\ Addis Ababa, Ethiopia
}

\begin{abstract}
The purpose of this study is to examine the effect of business process reengineering practices on employee performances. Egalitarian leadership cooperative working environment, top management commitment, the use of information technology, and resistance to change are major variables dealt in the study. Methods designed were descriptive and explanatory. probability sampling techniques and non-probability were used. Sample size determined scientifically was 110 . The probability sampling technique used were stratified and simple probability technique. source of data was primary and secondary. Data collection tools were structured interview and questionnaires. Data was analysed by both descriptive and inferential analysis methods. The study achieved 92.7\% response rate since 102 questionnaires were filled and returned out of 110 questionnaires distributed. Statistical package social science (SPSS21 version) software used to enter data. Pearson correlation and multiple linear regression model used for inferential analysis methods. Finally, conclusion was egalitarian leadership, cooperative working environment, top management commitment and use of information technology have significant effect on employee performances and resistance to change has insignificant effect on employee performances. A recommendation suggested on the findings were the organization should efficiently share the vision, top managers should participate employees in decision making, update information technology, making conducive working environment to achieve employee performances effectively.
\end{abstract}

Keywords: Business process reengineering, leadership, top managements, employee performances

DOI: $10.7176 / \mathrm{EJBM} / 13-5-01$

Publication date:March $31^{\text {st }} 2021$

\subsection{Introduction}

Marjanovic(2000) shared the fact that the contemporary business process environment in which an organization exists becoming increasingly dynamic. The pressing needs to improve the existing business process reengineering and employee performance in organization results in the appearance and application of a new field named business process reengineering.

As Revere (2004) stated, in spite of their slight difference, the concept of redesigning how business performances strategic process. Because process was at heart of the management philosophy the term business process reengineering was adopted.

\section{2 statement of the problem}

As Hammer and Champy(1993) emphasized every line up in every organization affects the response of their work force performances.

In Ethiopia polidano (1990) indicated that the commitment to reform is often criticized as in adequate, since many institutions are lacking visionary leadership, organizations are operating under poor conditions the necessary staff in many organizations are lacking and are not consulted and motivated when they should be and the accountability relationship between government and public service provider not been clarified.

In this regard, many studies have explained the effect of business process reengineering practices on the employee performances. Based on their findings: some of their findings are Majanovic(2004), Crowe(2002), Grant (2002) problems related with egalitarian leadership top management commitment, cooperative working environment, the use of information technology, resistances to change are repeatedly occurred in different countries in different organizations. Furthermore, the effect of business process reengineering practices on performances of the organization Ethiopia public organizations was not much studied. The researchers motivated to conducted the study on the selected topic was, firstly, the effect of business process reengineering practices on the employee performance of the organization was different from country to country and different from organization to organization context. Even though, some studies conducted in Ethiopia, more of these were focused at federal, regional and zonal levels. Thirdly, at woreda level there are several customers need services from employees at large but studies conducted were limited. Therefore, this study tried to fill the 
research gap of the effect of business process reengineering practices on the employee performance of the organization in Essera woreda.

\subsection{Hypotheses}

$>$ H1: There is positive and significant effect between egalitarian leadership and employee performance

$>$ H2: There is positive and significant effect between top management commitment and employee performance

$>$ H3: There is positive and significant effect between cooperative working environment and employee performance

H4: There is significant effect between the use of information technology and employee performance.

$>$ H5: There is significant effect between resistance to change and employee performance

\subsection{Objectives of study}

\subsubsection{General objective of the study}

This study aimed to explain the effect of business process reengineering practices on employee performances

\subsubsection{Specific objective of the study}

$>$ To explain the effect of egalitarian leadership on employee performance.

$>$ To explain the effect of top management commitment on employee performance.

$>$ To examine the effect of cooperative working environment on employee performance.

$>$ To explain the effect of the use of information technology on employee performance.

$>$ To explain the effect of resistance to change on the employee performance.

\subsection{Review of Related Literature}

\subsubsection{The Nature of Business Process Reengineering and Empirical Review}

According to Tarokh (2006) reveal that time is full of changes, transformation, unrest where all the rich suddenly emerge and collapse. All organization that desire sustainability need to respond for all forms of change in the environment accordingly.

\subsubsection{Evolution of Business Process Reengineering}

Marjanovic (2000) shared the fact that the contemporary business process environment in which a organization exist is becoming increasingly dynamic. The pressing needs to improve the existing business process and employee performance in an organization results in the appearance and application of new field named business process reengineering.

Hammer and Champy (1990) announced the conception and birth of business process reengineering. This is linked with end of the $20^{\text {th }}$ century.

\subsubsection{Egalitarian Leadership}

This factor fosters a set of common beliefs that gives value to positive employee performance. It allows change to take place with little resistance. The major components of such leadership to affect employee performance are Motwani (2005) and Lee (1995) shared vision /information, open communication, confidence and trust in subordinates and constructive use of employee idea.

\subsubsection{Collaborative Working Environment}

Crowe(2002) has shown collaborative work environment as one of the critical success factors in business process reengineering project. Tatisiopoulos and Panayiotou (2000) recommend employee should work together in the department or bureau, the same time, and interacting in a friendly way with each other. Crowe (2003) and Maull(2003) believed in order to work in a cooperative environment and interact in a friendly way, employees should trust each other, and be assured that the top management recognize their role.

\subsubsection{Top management Commitment}

Dixon(1994) advised the magnitude of implementing reengineering process requires an absolute top management commitment. Managers need to devote the necessary time, money and resources to bring the required changes. Grant (2002) argued top management should have a clear knowledge about the current situation of the organization.

Crowe (2002) indicated the necessity to have sufficient knowledge about the business process reengineering. In order to have a flourishing business process reengineering, top management should communicate with employees.

\subsubsection{Use of Information Technology}

Hammer and Champy(1990) the use of information technology is to challenge the assumption inherent in the work process that have existed since before the advent of modern computer and communication technology. They argued that at the heart of reengineering there is the idea of discontinuous thinking. Discontinuous thinking is a way to recognize and break away from obsolete rules and fundamentals assumption that underlie operations.

Shin and Jemalla(2002) mentioned adequate understanding of technology in redesigning business process is 
essential for proper selection of information technology plate form. Largely effective system, architecture, flexible, information technology infrastructure and proper installation of information technology components contributed to build a valuable information technology for better employee performance.

\subsubsection{Resistance to Change}

Davenport (1994) mentioned the major issues of this part are resistance to change. It is linked to management fear of losing authority, employee fear of losing job, scepticism about project result and uncomfortable feeling with the new working environment.

Hammer and champy(1993) have identified factors like failure to have a process perspective, fixed process which is not flexible enough to be responsible needs and requirements, not involving employees in decision making, assigning someone who does not aware of business process reengineering, technology limitation designing a project but with weak team and tricky communication.

\section{5,8 Employee Performance}

Hammer and Champy(1993) public bureau organization are those involved in providing communal service. Reengineering has become accepted approach in the reform efforts of public organizations. Originally it is conceived for radical changes in improving business process, operation and competitiveness. With this intention, Department of the interior (2004) identified employee performance indicators: of which understanding and adhering to organization policy and procedures ,effective use of resource, number of customers served in a given time, informing supervisors, project initiation, and logical and creative solution to problems, working with other employees and receptive to new ideas and concepts will be used.

\subsubsection{Conceptual Framework.}

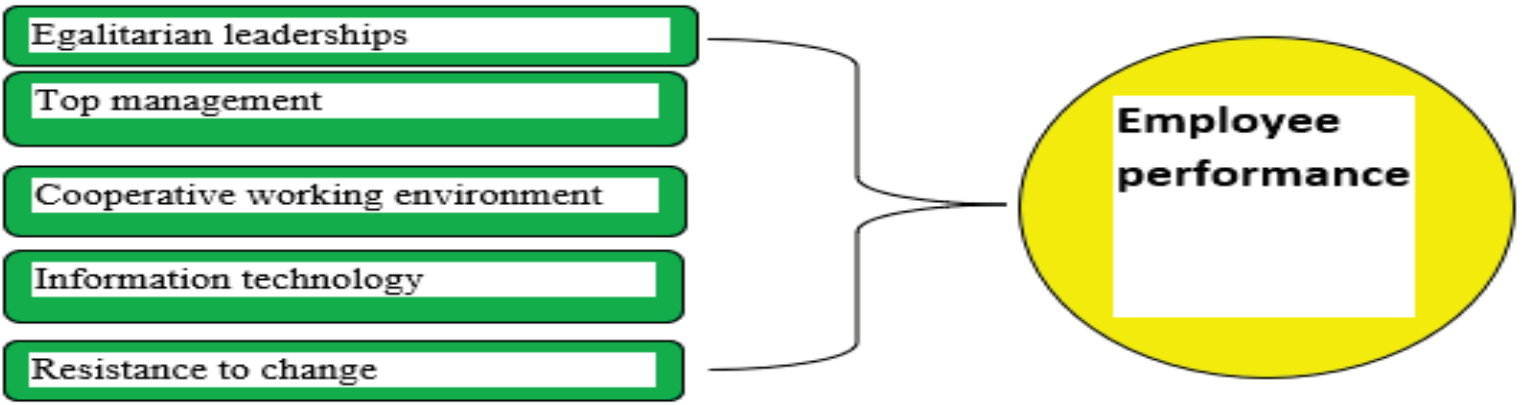

Figure 1: conceptual Framework

\subsection{Research design and Methodology \\ 1.6.1 Research design}

According to Kothari (2004) research is the arrangement of conditions for collection and analysis of data in a manner that aims to combine relevance to the research purpose with economy in procedures. It is the conceptual structure with in which research is conducted; it institutes the blue print for the collection, measurement and analysis of data.

As the study intended to explain cause and effect between independent and dependent variables in the study area. Explanatory research design was used in this study. Both qualitative and quantitative approaches were employed for the study.

\subsubsection{Target population and sample size determination}

The total population of this study focused on the employees of woreda two administrative offices namely public service and human resource development and health office employees of 151. According to Kothari (2004) two general approaches to sampling are used in social science research i.e. Probability sampling or non-probability sampling. This study employed both probability and non-probability sampling techniques. Judgemental non probability method was used to select public service and human resources office and health office from woreda and stratified sampling was used to select sample from each sample offices and convenience each respondent from the total sample to respond questions.

\subsubsection{Sample Size}

The study used a simplified formula provided by Yamane (1967) in order to determine the required sample size at $95 \%$ confidence level, degree of variability $=0.5$ and with the level of precision of $=5 \%$.

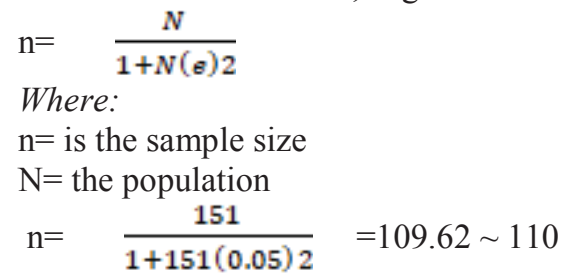


Following the formula provided the sample size considered for this study is 110 .

\subsubsection{Data sources and Collection Methods}

In this research primary data sources were used. The primary data sources obtained from questioners and structured interviewed. In line with the objective of the study the research established Likert scale questioners and structured interview to collect data. Likert scale a very popular rating scale for measuring ordinal data in social science research using a 5-point Likert scale, respondents express their level of agreement or disagreement assigned ( $1=$ strongly disagree, $2=$ disagree, $3=$ neither agree nor disagree, $4=$ agree, $5=$ strongly agree).

\subsubsection{Data analysis}

The study employed inferential statistical analysis. According to Kothari (2004) by analysis mean the collection of certain indices or measures along with searching for patterns of relationship that exist among the data, groups. Analysis particularly, in the case study or experimental data, involves estimating the values of identified parameters of the population and testing of hypothesis for drawing inferences. Analyses may, therefore be characterized as inferential by using statistical package for social science (SPSS version 21). The relationship between independent and dependent variables by Pearson's correlation and multiple linear regression inferential analyses methods at 5\% significance level.

\subsubsection{Research Model}

To determine the influence of each predicator on dependent variable; multiple linear regression model is used.

Model equation; $Y=\beta 0+\beta 1 \mathrm{X} 1+\beta 2 \times 2+\beta 3 \times 3+\beta 4 \times 4+\beta 5 \times 5+\varepsilon$

The $\mathrm{Y}$ is the dependent variable employee performance

$\mathrm{B} 0$ is the $\mathrm{y}$-intercept; $\beta 1, \beta 2 \ldots \mathrm{B} 5$ are coefficients of predictors; $\mathrm{x} 1, \mathrm{x} 2 \ldots \mathrm{x} 5$ are independent variables $(\mathrm{x} 1$ is egalitarian leadership; $\mathrm{x} 2$ is top management commitment; $\mathrm{x} 3$ is cooperative working environment; $\mathrm{x} 4$ is use of IT; $x 5$ is resistance to change)

\subsection{Data Analysis and Discussion}

In this study ,203 questioners were distributed to respondents and 195 questioners successfully filled and returned, they were considered as the sample with a response rate of $96 \%$.

\subsubsection{Inferential Statistical Analysis}

\subsubsection{Correlation analysis}

The study used the Pearson correlation coefficient to determine the relation and strength of the correlation between the independent and dependent variables.

According to pallet (2003) a correlation coefficient enables one to quantify the strength of the linear relationship between variables. The coefficients are represented by ' $r$ ' and can be taken only the value range from -1 to +1 i.e. if $r=+1$ indicate a perfect positive correlation, and if $r=-1$ perfect negative correlation, and $\mathrm{r}=0$ no correlation. $\mathrm{R}=0.10$ to 0.29 weak relationship, and $\mathrm{r}=0.30$ to 0.49 moderate relationship and 0.5 to 1 strong relationship. The sign may negative or positive.

\begin{tabular}{|c|c|c|c|c|c|c|c|}
\hline & & Cooperative & Top mgt & IT & Resistance & Employee per & leadership \\
\hline \multirow{4}{*}{ Cooperative } & $\begin{array}{l}\text { Pearson } \\
\text { Correlation }\end{array}$ & & & & & & \\
\hline & Sig. (2-tailed) & & & & & & \\
\hline & & 102 & & & & & \\
\hline & Pearson & $.396^{* *}$ & 1 & & & & \\
\hline \multirow[t]{3}{*}{ Top mgt } & Sig. (2-tailed) & .000 & & & & & \\
\hline & & 102 & 102 & & & & \\
\hline & Pearson & $.853^{* *}$ & $.437^{* *}$ & 1 & & & \\
\hline \multirow[t]{3}{*}{ IT } & $\begin{array}{l}\text { Correlation } \\
\text { Sig. (2-tailed) }\end{array}$ & .000 & .000 & & & & \\
\hline & & 102 & 102 & 102 & & & \\
\hline & Pearson & $.646^{* *}$ & $210^{*}$ & $.572^{* *}$ & 1 & & \\
\hline \multirow[t]{3}{*}{ Resistance } & Sig. (2-tailed) & .000 & .034 & .000 & & & \\
\hline & $\mathrm{N}$ & 102 & 102 & 102 & 102 & & \\
\hline & Pearson & $.894^{* *}$ & $.481^{* *}$ & $.839^{* * *}$ & $.544^{* *}$ & 1 & \\
\hline \multirow[t]{3}{*}{ Employee per } & Correlation & 000 & 000 & 000 & إ & & \\
\hline & $\mathrm{N}$ & 102 & 102 & 102 & 102 & 102 & \\
\hline & Pearson & $.896^{* *}$ & $.422^{* *}$ & $.829^{* *}$ & $.624^{* *}$ & $.874^{* *}$ & 1 \\
\hline \multirow{3}{*}{ Leadership } & Correlation & & & & & & \\
\hline & Sig. (2-tailed) & .000 & .000 & .000 & .000 & .000 & \\
\hline & $\mathrm{N}$ & 102 & 102 & 102 & 102 & 102 & 102 \\
\hline
\end{tabular}


performance. The result reveals that there is positive and significant relationship between business process reengineering practices and employee performance (sig. level 0.01 two tailed). Moreover, egalitarian leadership, use of information technology, cooperative working environment, resistance to change had positive and strong relationship with employee performance $(\mathrm{r}=0.874, \mathrm{r}=0.839, \mathrm{r}=0.544, \mathrm{r}=0.894)$ respectively. The remaining top management commitment had moderate and positive relationship with the performance of the organization.

\subsubsection{Results of Multiple Linear Regressions Model Analysis}

From the table 2 below the results indicated that independent variables explained $84.2 \%$ of the variation on employee performance of public organizations in Essera woreda as shown by the adjusted R square. This implies that $84.2 \%$ of the corresponding change on employee performance can be explained by a unit change in the practices of egalitarian leadership, top management commitment, cooperative working environment, use of information technology and resistance to change. $\mathrm{R}$ square values from the table 2 below shows that the variations in the employee performance account for $85 \%$ egalitarian leadership, top management commitment, cooperative working environment, use of information technology and resistance to change. Other factors account for $15 \%$ for the variation of employee performance in the Essera woreda. The $\mathrm{R}$ value is the correlation coefficient of the independents (egalitarian leadership, top management commitment, cooperative working environment, use of information technology and resistance to change) and the outcome or dependent variable (employee performance) was 0.922. The independents' overall impact on employee performances is 0.922 .

Table 2 Model Summary

\begin{tabular}{|l|r|r|r|r|}
\hline Model & R & R Square & Adjusted R Square & Std. Error of the Estimate \\
\hline 1 & $.922^{2}$ & .850 & .842 & .27976 \\
\hline
\end{tabular}

a. Predictors: (Constant), leadership, top mgt, Resistance, IT, cooperative

Table 3 Anova

\begin{tabular}{|ll|r|r|r|r|r|}
\hline Model & Sum of Squares & Df & Mean Square & F & Sig. \\
\hline \multirow{2}{*}{1} & Regression & 42.548 & 5 & 8.510 & 108.730 & $.000^{\mathrm{b}}$ \\
& Residual & 7.513 & 96 & .078 & & \\
& Total & 50.061 & 101 & & & \\
\hline
\end{tabular}

a. Dependent Variable: Employee performance

b. Predictors: (Constant), leadership, top mgt, Resistance, IT, cooperative

The ANOVA table 3 above shows that the computed F-statistic is 108.730 with an observed significance level of less than 0.001 . Thus, the hypothesis that there is positive and significant effect between the predictors (egalitarian leadership, top management commitment, cooperative working environment, use of information technology and resistance to change) and dependent variable (employee performance) was accepted. The general objective of the study was achieved.

\section{Normality test by using histogram}

Empirical rule for asymmetrical, bell-shaped frequency distribution, approximately 68 percent of the observations will lie within plus and minus one standard deviations of the mean; about $95 \%$ of the observations will lie within plus and minus two standard deviation of the mean; and practically all (99.7 percent) will lie within plus minus three standard deviations of the mean (DoglasA.et.al., 2006) 


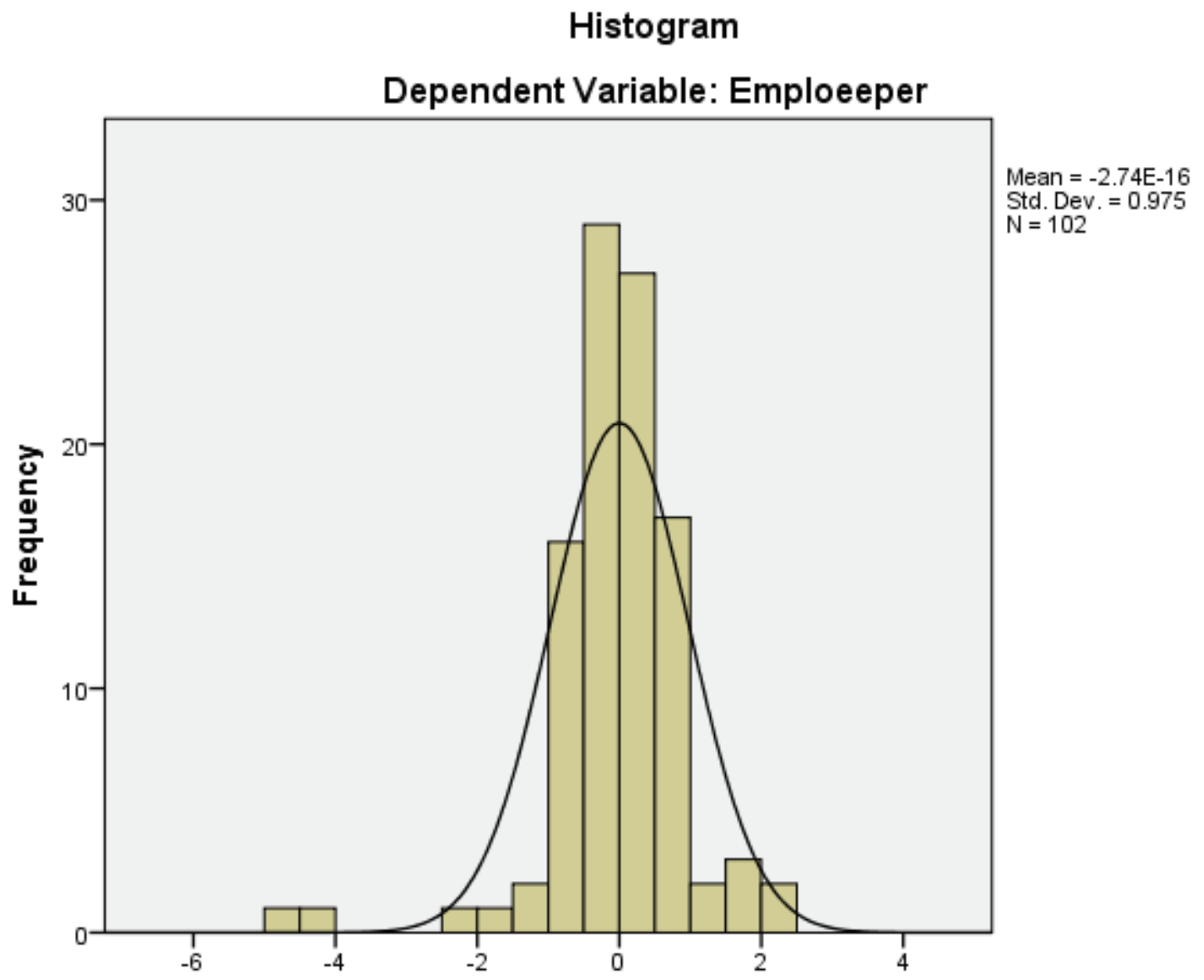

\section{Regression Standardized Residual}

Figure 2: normality test

According to empirical rule $95 \%$ of the observations lie in will lie within plus minus two standard deviations of the mean imply the distribution was normal.

\section{Multicollinearity tests}

According to Andy Field (2009) SPSS produces various co linearity diagnostics, one of which is the variance inflation factor (VIF) What's more, if the average VIF is greater than 1, then multicollinearity may be biasing the regression model. Related to the VIF is the tolerance statistic, which is its reciprocal (1/VIF). As such, values below 0.1 indicate serious problems. The multicollinearity checked in this study shows the tolerance value greater than 0.1 and the variance inflation factor (VIF) greater than 1 indicates multicollinearity was good.

\begin{tabular}{|c|c|c|c|c|c|c|c|c|}
\hline \multirow{2}{*}{\multicolumn{2}{|c|}{ Model }} & \multicolumn{2}{|c|}{$\begin{array}{c}\text { Unstandardized } \\
\text { Coefficients }\end{array}$} & \multirow{2}{*}{\begin{tabular}{c|}
$\begin{array}{c}\text { Standardized } \\
\text { Coefficients }\end{array}$ \\
Beta
\end{tabular}} & \multirow[t]{2}{*}{$\mathrm{T}$} & \multirow[t]{2}{*}{ Sig. } & \multicolumn{2}{|c|}{$\begin{array}{c}\text { Collinearity } \\
\text { Statistics }\end{array}$} \\
\hline & & B & Std. Error & & & & Tolerance & VIF \\
\hline \multirow{6}{*}{1} & (Constant) & .261 & .094 & & 2.783 & .006 & & \\
\hline & Cooperative & .453 & .095 & .488 & 4.790 & .000 & .151 & 6.642 \\
\hline & Topmgt & .088 & .039 & .101 & 2.271 & .025 & .789 & 1.267 \\
\hline & IT & .164 & .074 & .179 & 2.231 & .028 & .243 & 4.111 \\
\hline & Resistance & -.071 & .047 & -.080 & -1.520 & .132 & .567 & 1.764 \\
\hline & leadership & .272 & .087 & .296 & 3.138 & .002 & .176 & 5.676 \\
\hline
\end{tabular}

a. Dependent Variable: Employee performance

The model equation; $Y=\beta 0+\beta 1 \mathrm{X} 1+\beta 2 \times 2+\beta 3 \times 3+\beta 4 \times 4+\beta 5 \times 5+\varepsilon$

$\mathrm{Y}$ is the dependent variable customer loyalty $\beta 0$ is the $y$-intercept; $\beta 1, \beta 2 \ldots \ldots+\beta 5$ are coefficients of predictors; $\mathrm{x} 1, \mathrm{x} 2 \ldots \mathrm{x} 5$ are independent variables ( $\mathrm{x} 1$ is cooperative; $\mathrm{x} 2$ is top $\mathrm{mgt}$; $\mathrm{x} 3$ is IT; $\mathrm{x} 4$ is resistance; $\mathrm{x} 5$ is leadership) To predict employee performance, the study used the value presented in the unstandardized 
coefficient column. Using $\beta 0$ and $\beta 1, \beta 2, \beta 3, \beta 4$ and $\beta 5$ values, the prediction equation is:

$Y=0.261+0.453 \times 1+0.088 \times 2+0.164 \times 3-0.071 \times 4+0.272 \times 5$

From the model equation above a unit change in the cooperative working was resulting in the $45.3 \%$ change in the employee performance in Addis Ababa city administration Akaki kality sub city at significance level of 0.000. Therefore, the hypothesis that cooperative working has significant and positive impact on employee performance was accepted and positive impact on employee performance. From the model equation above a unit change in top mgt was explaining the employee performance $8.8 \%$ in the Addis Ababa city administration Akaki kality sub city at significance level of 0.025 . Thus, the hypothesis of the top mgt had positive and significant effect on employee performance was accepted at the significance level 0.025 . The employee performance was explained by resistance to change the in -0.071 coefficients. The hypothesis of resistance to change had insignificant impact on employee performance was rejected at significance level 13\% significance level should be less than 5\%. The IT and employee performance had the significant relation was explained by 0.164 . The hypothesis IT and employee performance had positive and significant impact was accepted at the significance level of 0.028 . A unit change in the leadership resulted in 0.272 changes of the employee performance. The hypothesis leadership had the positive and significant impact on the employee performance was accepted at the significance level 0.002 .

\subsubsection{Conclusions}

The general objective of this study was to explain the impact of business reengineering practices on employee performance. Based on the findings of the study the following conclusions were drawn.

$>$ The correlation result shows that the correlation coefficient of 0.874 at the $p$ value of 0.01 two tailed shows that there was positive and strong relationship between leadership and employee performance. The regression result shows that a unit change in the egalitarian leadership was resulting in the $27.2 \%$ change in the employee performance at significance level of 0. 002.Therfore, egalitarian leadership had significant impact on employee performance in study area.

$>$ The correlation result shows that correlation coefficient of 0.894 at $p$ value 0.01 two tailed shows that there was positive and strong relationship between the cooperative working and employee performance. The regression result shows that a unit change in the cooperative working was resulting in the $45.3 \%$ change in the employee performance at significance level of 0 . 000.Therefore, cooperative working environment had significant impact on employee performance in study area.

$>$ The correlation result shows that the correlation coefficient of 0.481 at $\mathrm{p}$ value 0.01 two tailed shows that there was positive and moderate relationship between top management and employee performance. The regression result shows that a unit change in top management was explaining the employee performance $8.8 \%$ at significance level of 0.025 .Therfore, top management had significant impact on employee performance in study area.

$>$ The correlation result shows that correlation coefficient of 0.839 at $p$ value 0.01 two tailed shows that there was positive and strong relationship between IT and employee performance. The regression result shows that IT and employee performance had the significant impact was explained by 0.164 . Therefore, IT had significant impact on employee performance in study area.

$>$ The correlation result shows that correlation coefficient of 0.544 at $p$ value 0.01 two tailed shows that there was moderate relationship between resistance to change and employee performance. The regression result shows that resistance to change had insignificant impact on employee performance was rejected at significance level 13\% significance level should be less than 5\%. Therefore, resistance to change had insignificant impact on employee performance in study area.

\subsubsection{Recommendations}

According to conclusion on the findings, recommendations are forwarded for improvements in the business process practice to effectively enhance employee performances:

$>$ The researchers recommended that for improvements in egalitarian leadership variable the organization in the study area should have shared vision or information, open communication, confidence and trust with employees, and provide accurate information for their employees and use employee ideas in order to improve employee performances.

$>$ The researchers recommended that for improvements in collaborative working environment variable organization should work in friendly manner, build trust with each other, build teamworking habit and managers should recognize employee's effort towards organization's plan achievement, manager should build confidence on employees for improvement in their performances.

$>$ The researchers recommended that for improvements in top management commitment variable the managers should devote time, effort and all the necessary resources to bring expected change in organization, managers should have sufficient knowledge about business process projects and should 
communicate openly with organizational members to achieve its intended results.

$>$ The researchers recommended that for improvements in use of information technology variable the organization should properly implement information technology, understand the role of information technology for implementation of business process reengineering projects and communicate the use of information technology for the organization members like save time, reduce cost and error, easily transferring and exchange of information for improvement of employee performances.

$>$ The researchers recommended that for improvements in resistance to change variable the organization should give adequate information the business process reengineering projects and give information about the benefits of the project both for the employees and organization, the organization should encourage the interest of employees, should give training for employees about the change that the business process reengineering projects.

\subsubsection{Future research direction}

The coefficient of determination shows that the variations in the employee performance account for $85 \%$ leadership, cooperative, top mgt, IT and resistance to change. Other factors account for $15 \%$ for the variation of employee performance as shown by the adjusted $\mathrm{R}$ square. Therefore, other researchers focus on the other factors such as political system, reward system, employee commitment, organizational culture etc.

\section{References}

Ahmed, H., Francis,A., \&Zairi, M.,(2007).Business process reengineering: Critical success factors in higher education, Business process management journal, Vol.13 (No.3).

Attaran, M.,(2000). Information technology and business-process redesign. Business Process Management Journal,Vol.9(No.4).

Davenport, T. H., (1993). "Need radical innovation and continuous improvement? Integrate process reengineering and TQM", Planning Review, Vol.21(No.3).

Davenport, T. H., \& Short, J. E., (1990). "The new industrial engineering: information technology and business process redesign”, Sloan Management Review,Vol.31(No.4).

Dixon, J., Arnold, P., Kim,J., \& Mulligan, P.,(1994). Business process reengineering: improving in new strategic directions, California management review.

DoglasA.et.al. (2006). basic statistics for business and economics. New York: Mc Graw Hill.

Field, A. (2009). Discovering Statistics Using Spss. London: SAGE Publications Ltd.

Gideon, E. (2015). Environmental Factors Affecting Procurement Performance in County

Ginn, D., \&Barlog, R., (1994). Reducing complexity and working with bottlenecks improves an oil refinery's engineering performance. National Productivity Review, Vol.13(No.1).

Grant,D.,(2002). A wider view of business process reengineering, Communications of the ACM, Vol.45(No.2).

Hammer, M., \&Champy, J.,(1993). Reengineering the corporation: a manifesto for business revolution. Nicholas Breaey Publishing, London.

Hammer, M., \& Stanton, S., (1995). The reengineering revolution. Happer Collins, New York, NY.

Kothari, C. (2004). Research Methodology :methods and techniques. new delhi: New Age international publisher

Lee, J., (1995).An exploratory study of organizational/managerial factors influencing business process reengineering implementation: an empirical study of critical success factors and resistance management. University of Nebraska, Lincoln,NE.

Yamane, Taro (1967). Statistics: an introductory analysis. New York: Harper \& Row 